\title{
UNSTEADY MHD NATURAL CONVECTIVE BOUNDARY LAYER FLOW AND HEAT TRANSFER OVER A TRUNCATED CONE IN THE PRESENCE OF PRESSURE WORK
}

\author{
C.K. Ajay, A.H. Srinivasa \\ Department of Mathematics, Maharaja Institute of Technology Mysore \\ S R Patna 571477, India \\ ajayarkesh@gmail.com,ahsydv@gmail.com
}

Received: 3 October 2019; Accepted: 29 March 2020

\begin{abstract}
The aim of the present paper is to analyse the effect of MHD on unsteady natural convection boundary layer flow and heat transfer over a truncated cone in the presence of pressure work. Suitable transformation is utilized to form a system of coupled non-linear partial differential equations for governing both the flow and heat transfer. These equations have been solved numerically by utilizing an implicit finite difference scheme along with quasilinearization method. Here, the computed numerical results are displayed graphically in terms of the local Nusselt number, skin friction, temperature distribution, and velocity distribution for various values of the magnetic and pressure work parameters along with the fixed Prandtl number.
\end{abstract}

MSC 2010: 76W05,76R10

Keywords: convection, pressure work, truncated cone, MHD, Prandtl number

\section{Introduction}

The study of the natural convection boundary layer flow is considered one of the most basic flows in fluid mechanics. This is seen in many heat circulation patterns in nature. Flow and heat transfer aspects are of considerable interest in several engineering applications like design of spacecrafts, design of solar energy collectors, power transformers and steam generators similar to atmospheric and oceanic circulations. The discussion and analysis of natural convection flows and pressure work impacts are generally ignored but here we have considered the impact of pressure work on a natural convective flow along a vertical circular cone.

A few have researched laminar natural convection flows, particularly in the field of non-uniform surface temperature $[1,2]$ built up the basic relationship for similar solutions on isothermal axisymmetric shapes and demonstrated the same for the flow past a vertical cone which provides a similar answer. Subsequently, 
many investigators [3-9] have done a great deal of work on the cone over the last few years. Further some pressure work effect problems over a cone has been studied in the articles $[10,11]$. Also the impact of pressure work on free convection flow over a truncated cone has been recently studied by [12].

There has been extraordinary enthusiasm for the investigation of MHD flow and heat transfer in any medium because of the impact of applied magnetic field on the control of the boundary layer flow and also on the output of many systems using electrically conductive fluids. This sort of flow has grabbed the interest of many investigators [13-18] because of its applications in MHD generators, plasma studies, crystal growth and design for cooling of nuclear reactors.

The effect of unsteadiness is not considered in all the above published works [1-18]. In the present study, the unsteady MHD laminar boundary layer flow and heat transfer over a truncated cone in the presence of pressure work shall be analyzed. Also, nowadays, many researchers have considered nanofluid for heat transfer applications [19-21].

\section{Mathematical formulation}

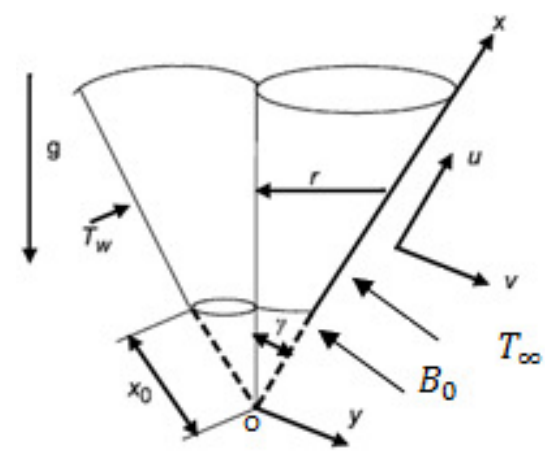

Fig. 1. Co-ordinate system \& flow configuration

Consider the unsteady two dimensional laminar boundary layer flow near a vertical truncated cone (with half angle $\gamma$ ) is as shown in Figure 1. In the coordinate system $(x, y), \mathrm{O}$ is the vertex of the full cone called origin, $x$ is the co-ordinate measurement from ' $\mathrm{O}$ ' along the entire cone surface and $y$ is the coordinate normal to the truncated cone surface. Here, let $x_{0}$ be the distance of the leading edge of the truncated cone which is measured from the ' $\mathrm{O}$ '. Moreover, it is assumed that the thickness of the boundary layer is small when compared to a local radius $(r)$ about a truncated cone. The distance from the local radius to a point in the boundary layer can be represented by $r=x \sin \gamma$. A magnetic field $B_{0}(x)$ is applied in the direction that is normal to the surface of the isothermal truncated cone in which it is assumed that the magnetic Reynolds is minute, hence the induced magnetic field can be ignored. The surface of the cone held at constant temperature $T_{w}$ is seen to be uniform and more than the ambient fluid temperature $T_{\infty}\left(T_{w}>T_{\infty}\right)$. 
Taking into account the aforesaid assumptions, the boundary layer equations governing the flow on a truncated cone can be expressed as:

$$
\begin{gathered}
\frac{\partial(r u)}{\partial x}+\frac{\partial(r v)}{\partial y}=0 \\
\frac{\partial u}{\partial t}+u \frac{\partial u}{\partial x}+v \frac{\partial v}{\partial y}=v \frac{\partial^{2} u}{\partial y^{2}}+g \beta \cos \gamma\left(T-T_{\infty}\right)-\frac{\sigma B_{0}^{2}}{\rho} u \\
\frac{\partial T}{\partial t}+u \frac{\partial T}{\partial x}+v \frac{\partial T}{\partial y}=\alpha \frac{\partial^{2} T}{\partial y^{2}}-\frac{T \beta u}{\rho C_{p}} \frac{\partial p}{\partial x}
\end{gathered}
$$

The initial and boundary conditions are given by:

$$
\begin{aligned}
& t<0: \quad u=0, v=0, \forall x, y \quad T=T_{w} \\
& t \geq 0: \quad u=0, v=0, T=T_{w}=T_{w 0}+w(\Delta T) \text { at } y=0 \\
& u=0, T=T_{\infty} \text { at } x=0 \\
& u \rightarrow 0, T \rightarrow T_{\infty} \text { as } y \rightarrow \infty
\end{aligned}
$$

Where $\partial p / \partial x=\rho g$ is the hydrostatic pressure.

Further,

$$
\begin{aligned}
& u=\frac{1}{r} \frac{\partial \psi}{\partial y}, v=-\frac{1}{r} \frac{\partial \psi}{\partial x} \\
& \xi=\frac{x^{*}}{x_{0}}=\frac{x-x_{0}}{x_{0}},\left(G r_{x^{*}}\right)^{1 / 4}=\frac{g \beta \cos \gamma\left(T_{w}-T_{\infty}\right) x^{* 3}}{v^{2}}, \eta=\frac{y}{x^{*}}\left(G r_{x^{*}}\right)^{1 / 4} \\
& T-T_{\infty}=\left(T_{w}-T_{\infty}\right) G(\xi, \eta), \psi=v r\left(G r_{x^{*}}\right)^{1 / 4} f(\xi, \eta), f^{\prime}=F=\frac{\partial f}{\partial \eta} \\
& u=\frac{v\left(G r_{x^{*}}\right)^{1 / 2}}{x^{*}} F=U_{r} F, \quad v=-\frac{v\left(G r_{x^{*}}\right)^{1 / 4}}{x^{*}}\left[\left(\frac{\xi}{\xi+1}+\frac{3}{4}\right) F+\xi \frac{\partial f}{\partial \xi}-\frac{1}{4} \eta F\right]
\end{aligned}
$$

Substituting the above transformations from equation (1) to (4), we acquire:

$$
\begin{aligned}
& F^{\prime \prime}+f F^{\prime}\left(\frac{\xi}{\xi+1}+\frac{3}{4}\right)+G-\frac{1}{2} F^{2}-M F-F_{t^{*}}\left(\frac{\xi}{1+\xi}\right)^{2}= \\
& \xi\left(F F_{\xi}-F^{\prime} f_{\xi}\right)+F F_{t^{*}} t^{*}\left(\frac{3}{2}-\frac{2 \xi}{1+\xi}\right)-F^{\prime} t^{*} f_{t^{*}}\left(\frac{3}{2}-\frac{2 \xi}{1+\xi}\right)
\end{aligned}
$$




$$
\begin{aligned}
& G^{\prime \prime}+\left(\frac{\xi}{\xi+1}+\frac{3}{4}\right) f G^{\prime} P_{r}-\left(\frac{\xi}{1+\xi}\right)^{2} p_{r} G_{t^{*}}-\varepsilon G F P_{r}= \\
& \xi\left(F G_{\xi}-G^{\prime} f_{\xi}\right) P_{r}+\left(\frac{-2 \xi}{1+\xi}+\frac{3}{2}\right) t^{*}\left(F G_{t^{*}}-G^{\prime} f_{t^{*}}\right) p_{r}
\end{aligned}
$$

The boundary conditions are:

$$
\begin{aligned}
& f^{\prime}=F=0, G=1+\omega \text { at } \eta=0 \\
& F=1, G=0 \text { as } \eta \rightarrow \infty
\end{aligned}
$$

Here the prime (') represents the derivative with respect to $\eta$. F and $G$ are the dimensionless stream function and temperature respectively. Gebhart [22] is the one, who utilized the pressure work parameter $\varepsilon=g \beta x^{*} / C_{P}$ first.

Respectively, the Skin friction and Heat transfer coefficients as Nusselt number, can be communicated, as

$$
\begin{aligned}
C_{f}=\frac{2 \tau_{w}}{\rho U_{r^{2}}} \text { where } \tau_{w}=\mu\left(\frac{\partial u}{\partial y}\right)_{y=0} \text { then } & \\
& \left(G r_{x^{*}}\right)^{1 / 4} C_{f}=2 F^{\prime}(\xi, 0)
\end{aligned}
$$

and $N u=-\frac{q_{w} x^{*}}{K\left(T_{w}-T_{\infty}\right)}$, where $q_{w}=-k\left(\frac{\partial T}{\partial y}\right)_{y=0}$

Then

$$
\frac{N u}{\left(G r_{x^{*}}\right)^{1 / 4}}=-G^{\prime}(\xi, 0)
$$

\section{Results and discussion}

The coupled nonlinear partial differential Eqs. (6) and (7) are solved alongside the boundary conditions (8) by utilizing an implicit finite difference scheme along with quasilinearization technique. Since the technique is described in [23], for the sake of brevity, the description of the same has been omitted here. We have compared our results with those of $\mathrm{Na}$ and Chiou [6] when $\varepsilon=0$ (i.e., in the absence of the pressure work parameter) for skin friction $\left(F^{\prime}\right)$ and heat transfer $(G)$ parameters as shown in Table 1, having different $\operatorname{Pr}=0.01$ and 0.72 , near the leading edge of the truanted cone $(\xi=0)$. Also, we have compared our results with those given by [12] for different pressure work parameters $\varepsilon=0.0,0.3,0.9$ and $\operatorname{Pr}=0.72$ without any magnetic field parameter $(\mathrm{M})$, for both skin friction and heat transfer coeffi- 
cients (see Fig. 2a and 2b). Our results are found to be in excellent conformity for correct four decimal places of accuracy with those of [6] and [12]. The obtained results are presented through the graphs for skin friction and heat transfer coefficients, velocity and temperature distributions having different values for magnetic and pressure work parameters in addition to a fixed Prandtl number $(\operatorname{Pr}=7.0)$ which is as shown in Figures 3-6.

Table 1. Comparison of $F^{\prime}$ and $-G$ for $\operatorname{Pr}=0.01,0.7$ at $\varepsilon=0, \xi=0$ with [6]

\begin{tabular}{|c|c|c|c|c|}
\hline \multicolumn{5}{|c|}{$\varepsilon=0$} \\
\hline & \multicolumn{2}{|c|}{ Ref. [6] } & \multicolumn{2}{c|}{ Present results } \\
\hline $\operatorname{Pr}$ & $F^{\prime}$ & $-\mathrm{G}$ & $F^{\prime}$ & $-\mathrm{G}$ \\
\hline 0.01 & 1.3948 & 0.0574 & 1.3947 & 0.0574 \\
\hline 0.7 & 0.9584 & 0.3533 & 0.9584 & 0.3532 \\
\hline
\end{tabular}
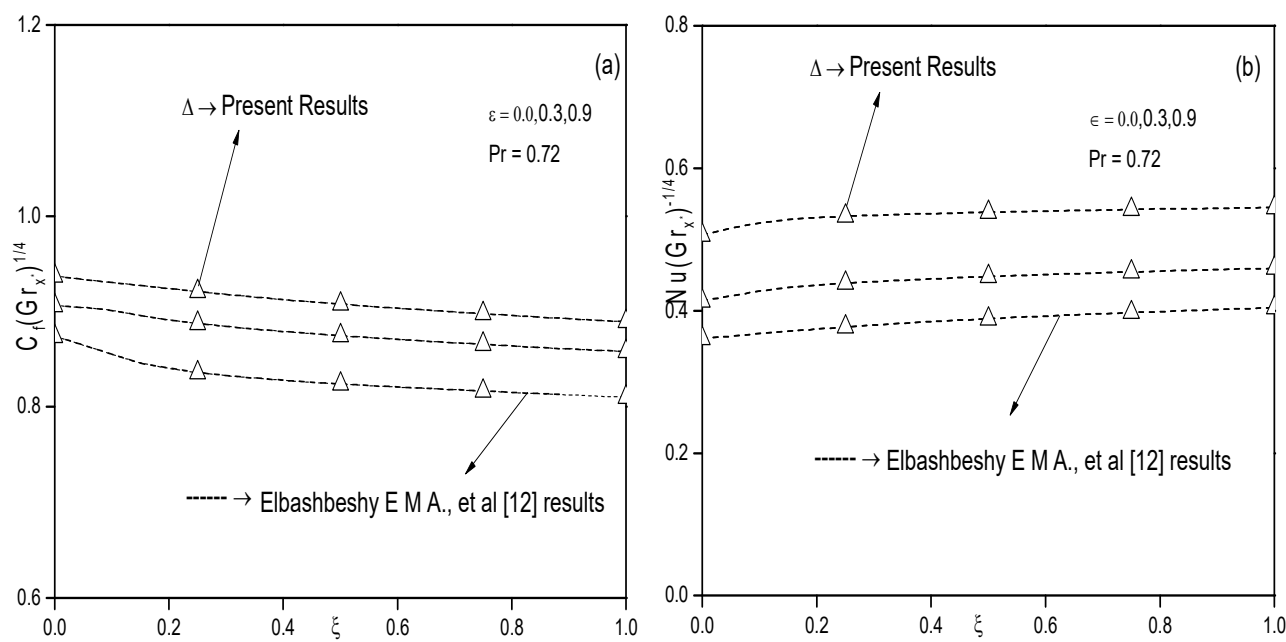

Fig. 2. Comparison of skin friction (a) and heat transfer coefficient (b) for Elbashbeshy et al. [12] when $\varepsilon=0.0,0.3,0.9$ with $\operatorname{Pr}=0.72$

Figure 3 shows the variation of skin friction coefficient $\left[C_{f}\left(G r_{x^{*}}\right)^{1 / 4}\right]$ and heat transfer coefficient $\left[N_{u}\left(G r_{x^{*}}\right)^{-1 / 4}\right]$ for various values of $\varepsilon=(0.0,0.25,0.5)$ alongside a stream wise location $t^{*}=1.0$ with fixed magnetic field parameter $\mathrm{M}=0.5$ and $\operatorname{Pr}=7.0$. It shows that the $C_{f}\left(G r_{x^{*}}\right)^{1 / 4}$ decreases and $N_{u}\left(G r_{x^{*}}\right)^{-1 / 4}$ rises with the enhancement of $\varepsilon$. The level of decrease in $C_{f}\left(G r_{x^{*}}\right)^{1 / 4}$ is $10.3 \%$ and increase in $N_{u}\left(G r_{x^{*}}\right)^{-1 / 4}$ is about $22.9 \%$. 

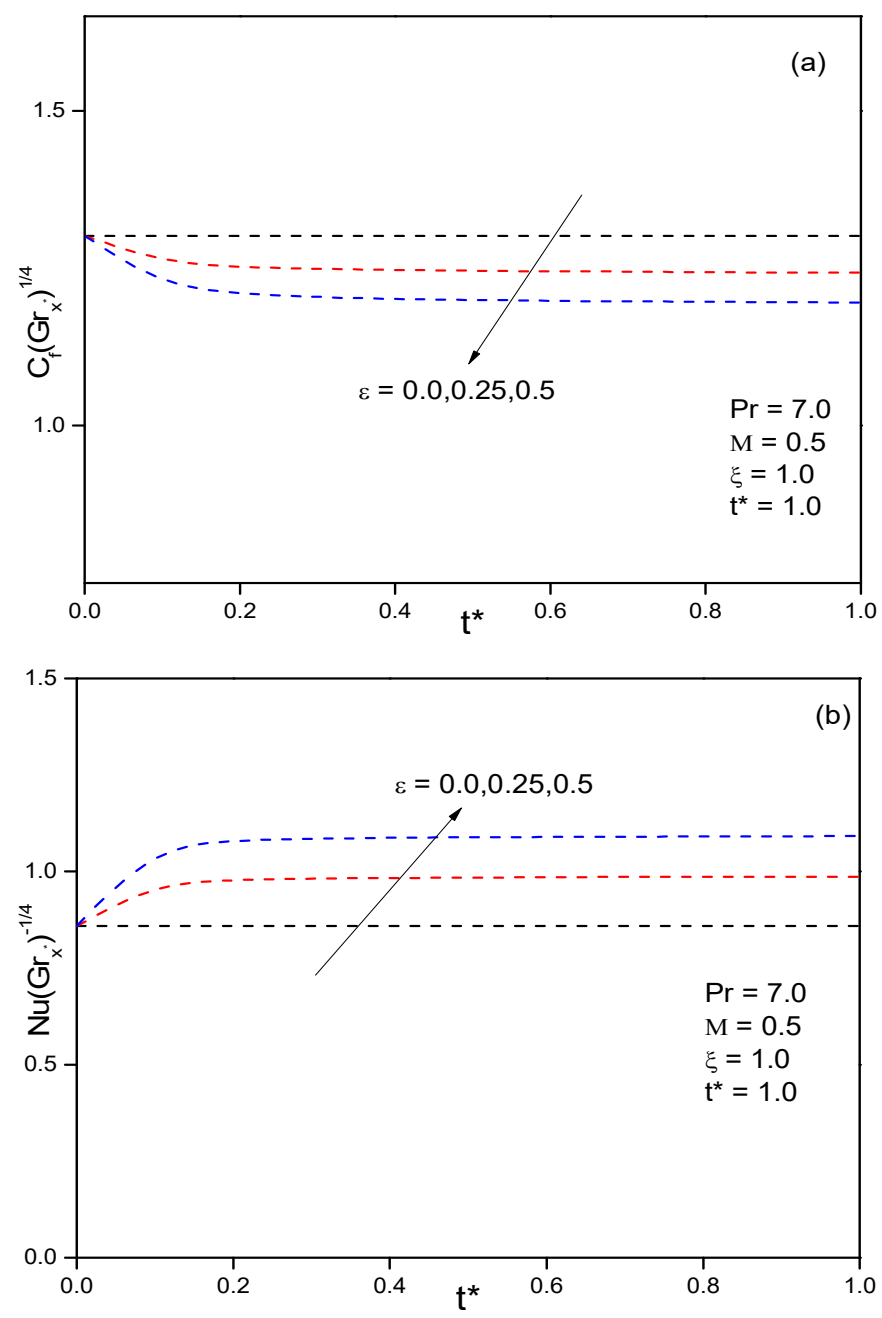

Fig. 3. Skin friction (a) and heat transfer coefficients (b) for various values of $\varepsilon$

Figures $4 \mathrm{a}$ and $4 \mathrm{~b}$ demonstrated the velocity and temperature distribution for different values of the pressure work parameter $(\varepsilon)$ and fixed Prandtl number $(\operatorname{Pr})$. From Figure 4a, it was observed that as $\varepsilon$ increases, the velocity rising up to the position of $\eta=0.9835$ and from that $\eta$ spot, velocities are slowly falling down and eventually reaching zero. It is also observed from Figure $4 \mathrm{~b}$ that the temperature profile decreases with $\varepsilon$. The maximum values of velocity witnessed as 0.1997 , $0.1877,0.1781$ for the $\varepsilon=0.0,0.25,0.5$ respectively at the same position $\eta=0.9835$ and the maximum velocity decreases by $1.56 \%$. Temperatures witnessed as 0.4807 , $0.4447,0.4158$ for the $\varepsilon=0.0,0.25,0.5$ respectively at the same position $\eta=0.9835$ and the temperature decreases by $6.49 \%$. Both velocity and temperature profiles are suppressed and compressed towards the surface of the truncated cone. Hence, 
it shows that both the thicknesses of thermal and momentum boundary layers are found to be diminishing.
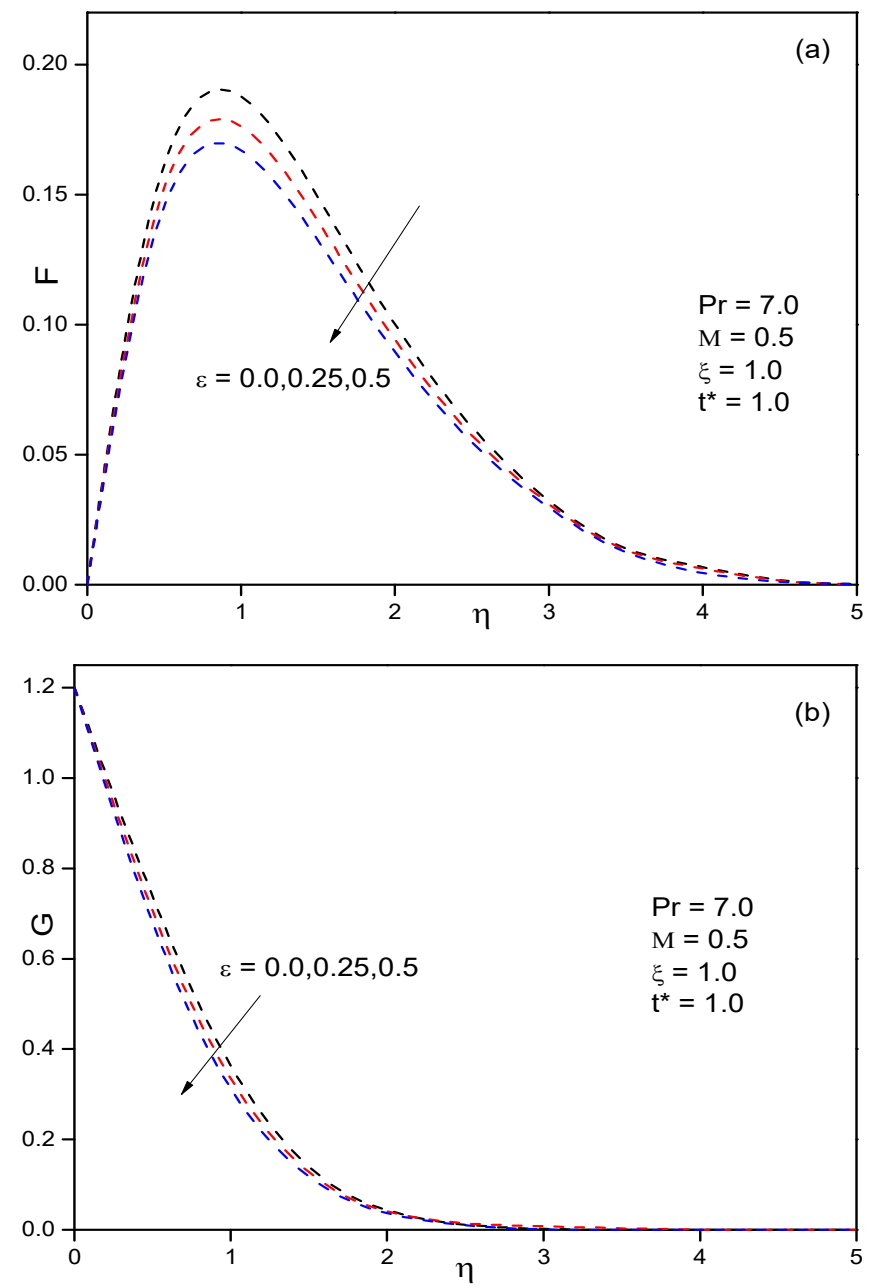

Fig. 4. Velocity profile (a) and temperature profile (b) at for various values of $\varepsilon$

The variation of skin friction $\left[C_{f}\left(G r_{x}^{*}\right)^{1 / 4}\right]$ and heat transfer co-efficient $\left[N_{u}\left(G r_{x^{*}}\right)^{-1 / 4}\right]$ for different values of $\mathrm{M}=(0.0,0.25,0.5)$ alongside fixed pressure work parameter $(\varepsilon=0.5)$ and Prandtl number $(\operatorname{Pr}=7.0)$ are shown in Figure 5. The impact of $\mathrm{M}$ on $C_{f}\left(G r_{x^{*}}\right)^{1 / 4}$ and $N_{u}\left(G r_{x^{*}}\right)^{-1 / 4}$ is less close to the apex of the cone and increases slowly with expanding the distance along the surface of the cone. The level of decrease in $C_{f}\left(G r_{x^{*}}\right)^{1 / 4}$ is about $12.68 \%$ and $N_{u}\left(G r_{x^{*}}\right)^{-1 / 4}$ is around $7.52 \%$. 

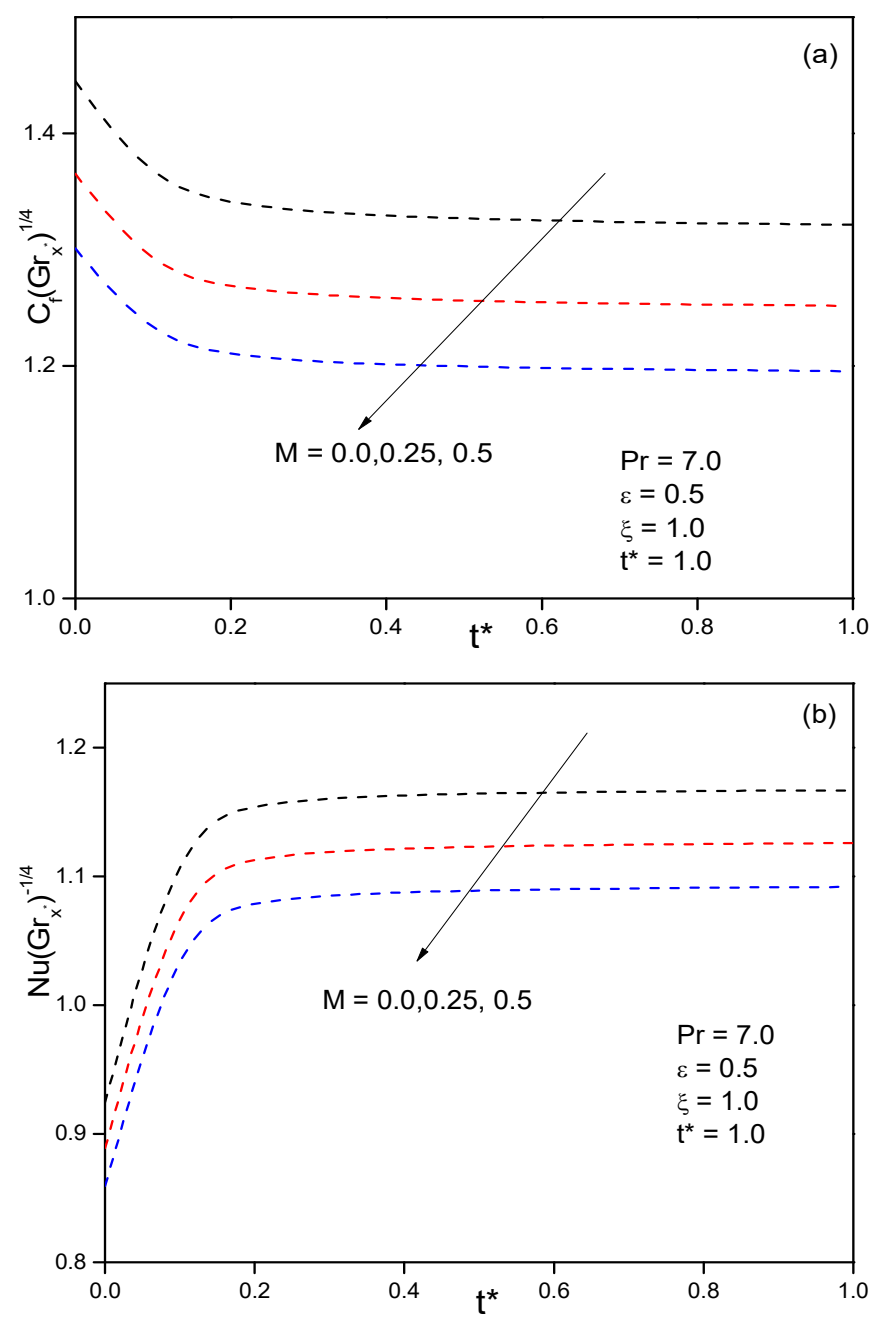

Fig. 5. Skin friction (a) and heat transfer coefficients (b) for various values of $M$

Figure 6 illustrates the variation of velocity and temperature profiles for various values of M. It is seen from the Figure 6a that for the values of magnetic field parameter the velocity decreasing up to the position of $\eta=4.1$ from the wall. At the $\eta=4.1$ velocity position, the velocity profiles intersect at one point, then cross the side and rise slightly with magnetic parameter $\mathrm{M}$. This is due to the velocity profiles having lower peak values for higher $M$ values. Also, a transverse magnetic field applied to an electrically conducting fluid ascends to a resistive kind of force known as the Lorentz force. This force has an inclination to slow the movement of the fluid in an axial direction. Furthermore, the change in the temperature profile in the $\eta$-direction (Fig. 6b) also shows the typical temperature profiles for free convection boundary layer flow that is temperature profile value is 1.2 at the boundary 
wall, then the temperature profile gradually decreases to the asymptotic value along $\eta$ direction. As such, we express that magnetic field causes the decline of the boundary layer.
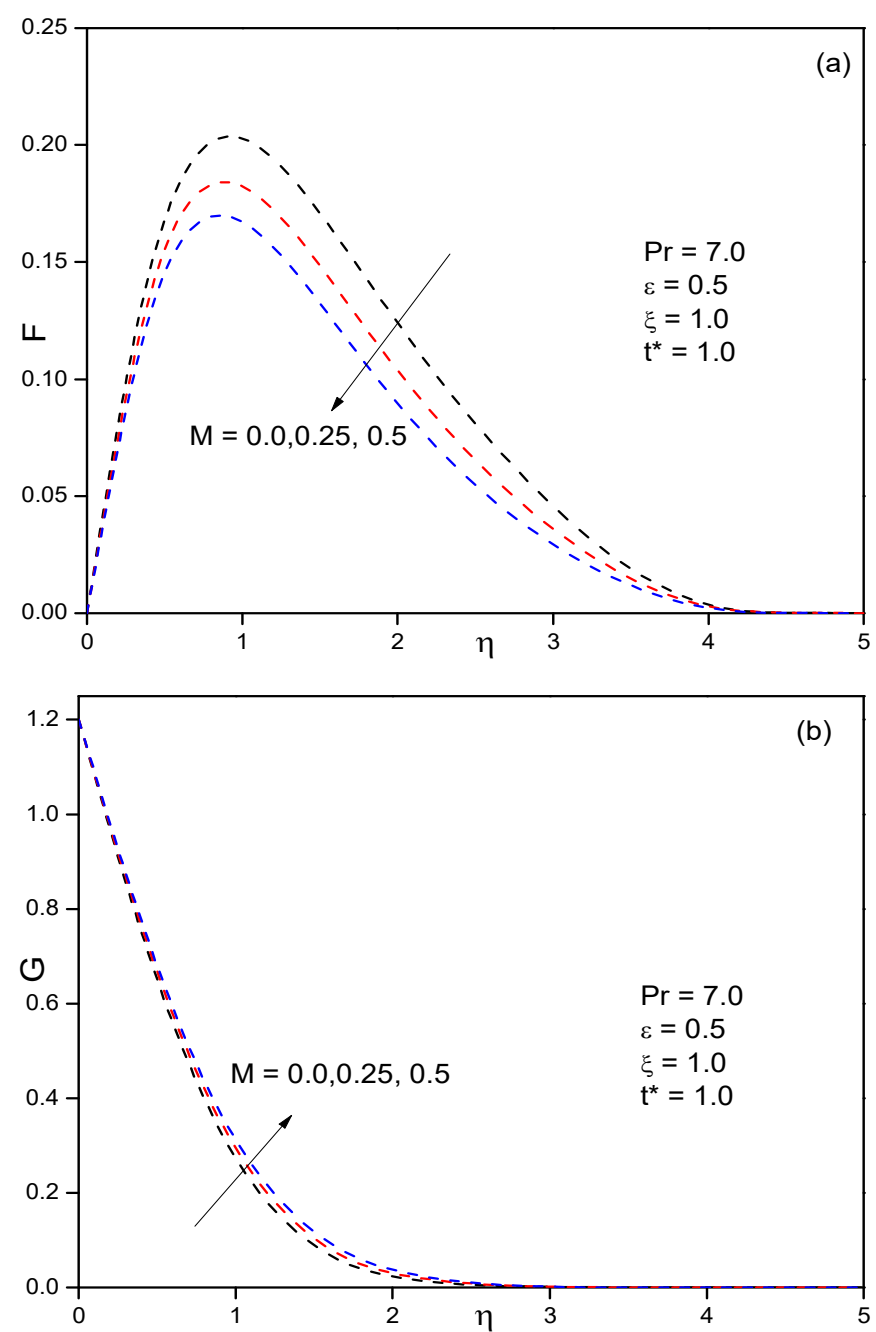

Fig. 6. Velocity profile (a) and temperature profile (b) for various values of $\mathrm{M}$

\section{Conclusions}

The effect of a magnetic field on unsteady natural convection flow from a truncated vertical cone along with a pressure work is considered here. From the current investigation the result can be summarized as follows: 
1. The skin friction coefficient decreases and heat transfer coefficient increases as the pressure work parameter rises for the fixed Prandtl number and a magnetic field.

2. Both velocity and temperature profiles deteriorates corresponding to stream wise locations as pressure work parameter enhances, hence thicknesses of thermal and momentum boundary layers are diminished.

3. With rising values of the magnetic field parameter with the fixed Prandtl number and pressure work parameter prompts a decline in both the skin friction and heat transfer coefficients.

4. Temperature distribution escalates but an opposite trend in velocity distribution as magnetic field parameter upsurges, hence the magnetic field causes the decline of the boundary layer.

\section{Nomenclature}

$\begin{array}{ll}C_{p} & \text { specific heat } \\ C_{f}\left(G r_{x^{*}}\right)^{1 / 4} & \text { skin friction coefficient } \\ g & \text { gravitational acceleration } \\ G r_{x^{*}} & \text { Grashof number } \\ N_{u}\left(G r_{x^{*}}\right)^{-1 / 4} & \text { heat transfer coefficient } \\ \mathrm{Pr} & \text { Prandtl number } \\ T & \text { fluid temperature } \\ T_{\infty} & \text { ambient fluid temperature } \\ p & \text { fluid pressure } \\ u, v & \text { fluid velocity components in } x, y \text { direction } \\ x & \text { stream wise coordinate } \\ y & \text { co-ordinate normal to the surface of the truncated cone } \\ B_{0} & \text { magnetic field } \\ \mathrm{M} & \text { dimensionless magnetic parameter } \\ \mathrm{F} & \text { dimensionless stream function } \\ \mathrm{G} & \text { dimensionless temperature }\end{array}$

\section{Greek letters}

$\alpha \quad$ thermal diffusivity

$\varepsilon \quad$ pressure work parameter

$\beta$ coefficient of thermal expansion

$\eta \quad$ similarity variable

$\mu \quad$ viscosity of the fluid

$\psi$ dimensionless stream function

$\xi$ dimensionless distance

$v$ kinematic viscosity 


\section{Acknowledgement}

The authors would like to express their gratitude to Principal and Management of the Maharaja Institute of Technology, Mysore-571477, for their benevolent support.

\section{References}

[1] Merk, E.J., \& Prinss, J.A. (1954). Thermal convection in laminar boundary I. Appl. Sci. Res., 4A, 3, 11-24.

[2] Merk, E.J., \& Prinss, J.A. (1954). Thermal convection in laminar boundary II. Appl. Sci. Res., 4A, 3, 195-206.

[3] Free, W.H. (1961). Convection similarity flows about two dimensional and axisymmetric bodies with closed lower ends. International Journal of Heat and Mass Transfer, 2, 1-2, 121-135.

[4] Hering, R.G., \& Grosh, R.J. (1962). Laminar free convection from a non-isothermal cone. International Journal of Heat and Mass Transfer, 5(11), 1059-1068.

[5] Roy, S. (1974). Free convection over a slender vertical cone at high Prandtl numbers. ASME Journal of Heat MassTransfer, 101, Feb., 174-176.

[6] Na, T.Y., \& Chiou, J. P. (1979). Laminar natural convection over a frustum of a cone. Applied Scientific Research, 35, 5, 409-421.

[7] Alamgir, M. (1979). Over-all heat transfer from vertical cones in laminar free convection: an approximate method. Transactions of ASME Journal of Heat Transfer, 101, 1, 174-176.

[8] Gorla, R.S.R., Chamkha, A., \& Ghodeswar, K. (2014). Natural convective boundary layer flow over a vertical cone embedded in a porous medium saturated with a nanofluid. Journal of Nanofluids, 3, 65-71.

[9] Sulochana, C., Ashwinkumar, G.P., \& Sandeep, N. (2016). Numerical investigation of chemically reacting MHD flow due to a rotating cone with thermophoresis and Brownian motion. International Journal of Advanced Science and Technology, 86, 61-74.

[10] Alim, M.A., Alam, M.M., \& Chowdhury, M.K. (2006). Pressure work effect on natural convection from a vertical circular cone with suction and non-uniform surface temperature. Mechanical Engineering, 36, 6-11.

[11] Alim, M.A., Alam, M.M., \& Chowdhury, M.K. (2007). Free convection from a vertical permeable circular cone with pressure work and non-uniform surface temperature. Nonlinear Analysis Modeling and Control, 12, 1, 21-32.

[12] Elbashbeshy, E.M.A., Emam, T.G., \& Sayeed, E.A. (2013). Effect of pressure work on free convection flow about a truncated cone. International Journal of Physical Sciences, 2, 01-10.

[13] Chakrabarathi, A., \& Guptha, A.S. (1979). A note MHD flow over a streachig permeable surface. Applied Mathematics, 37, 73-78.

[14] Reddy, P.S., Sreedevi, P., \& Chamkha, A. (2018). Magnetohydynamic boundary layer heat and mass transfer characterstic of nonofluid over vertical cone under convective boundary condition. International Journal of Propulsion and Power Research, 7(4), 308-319.

[15] Nadeem, S., \& Saleem, S. (2014). Theoretical Investigation of MHD nanofluid flow over a rotating cone: an optimal solutions. Information Sciences Letters, 3, 2, 55-62.

[16] Sriniva, A.H., \& Eswara, A.T. (2016). Effect of internal heat generation or absorption on MHD free convection from an isothermal truncated cone. International Alexandria Engineering Journal, 55(2), 1367-1373.

[17] Pullepu, Bapuji, \& Chamkha, A.J. (2009). Transient laminar MHD free convective flow past a vertical cone with non-uniform surface heat flux. Nonlinear Analysis: Modeling and Control, $14,4,489-500$. 
[18] Palani, G., \& Lalith Kumar, E.J. (2016). Magneto hydro dynamic free convective flow over a non isothermal vertical cone with Joule heating and viscous dissipation. Indian Journal of Science and Technology, 9(S1).

[19] Reddy, P.S., Sreedevi, P., \& Chamkha, Ali J. (2016). Heat and mass transfer flow of a nanofluid over an inclined plate under enhanced boundary conditions with magnetic field and thermal radiation. Heat Transfer-Asian Research, 46(7), 815-839.

[20] Prabavathi, B., Sudarsana Reddy, P., \& Bhuvana Vijaya, R. (2018). Heat and mass transfer enhancement of SWCNTs and MWCNTs based Maxwell nanofluid flow over a vertical cone with slip effects. Powder Technology.

[21] Sudarsana Reddy, P., Jyothi, K., \& Suryanarayana Reddy, M. (2018). Flow and heat transfer analysis of carbon nanotubes-based Maxwell nanofluid flow driven by rotating stretchable disks with thermal radiation. Journal of the Brazilian Society of Mechanical Sciences and Engineering, 40, 576 .

[22] Gebhart, B. (1962). Effects of viscous dissipation in natural convection. Journal of Fluid Mech., 14(2), 225-232.

[23] Inouye, K., \& Tate, A. (1974). Finite difference version of quasilinearization applied to boundary layer equations. AIAA Journal, 12, 558-560. 